\title{
Effectiveness of Dietary Advice to Increase Fish Consumption over a 12-Month Period*
}

\author{
Elizabeth P. Neale ${ }^{1}$, Amanda Cossey ${ }^{2}$, Yasmine C. Probst ${ }^{1}$, Marijka J. Batterham ${ }^{3}$, Linda C. Tapsell ${ }^{1}$ \\ ${ }^{1}$ Smart Foods Centre, University of Wollongong, Wollongong, Australia; ${ }^{2}$ Dietitian and Nutritionist, Blackheath, Australia; ${ }^{3}$ Statistical \\ Consulting Service, University of Wollongong, Wollongong, Australia. \\ Email: epn579@uow.edu.au
}

Received January $10^{\text {th }}, 2012$; revised February $20^{\text {th }}, 2012$; accepted February $29^{\text {th }}, 2012$

\begin{abstract}
Habitual fish consumption is associated with numerous health benefits; however, in Australia fish intake remains low. The aim of this study was to compare the effect of specific or general fish consumption recommendations on fish intake behavior over the duration of a 12-month clinical trial. Participants were randomized into a control group (general dietary advice), and two intervention groups (received dietetic advice to consume $180 \mathrm{~g}$ fish/wk), with one intervention group receiving LC omega-3 PUFA supplements. Dietary data was available for $\mathrm{n}=117$ at baseline, $\mathrm{n}=85$ at 3 months and $\mathrm{n}=63$ at 12 months. Total, fatty and lean fish intake (g/day) was calculated, and the change in fish intake between and within groups over the duration of the study was measured. Total fish consumption did not differ significantly between groups or within groups, however fatty fish intake was significantly greater in the intervention groups at three months $(\mathrm{p}=0.004)$. The proportion of study participants complying with fish intake recommendations was also highest at the three month time point for both intervention groups. Overall, compliance to fish intake recommendations was highest at the three month time point and appeared to be influenced by dietetic intervention. Provision of fish may increase compliance in future studies, however if research is to be translated to practice, behavioral approaches are required to increase fish intake in the long term.
\end{abstract}

Keywords: Compliance; Fish Consumption; Clinical Trial; Dietary Intervention

\section{Introduction}

Observational evidence has provided support for the health benefits of habitual fish consumption on a range of cardiovascular disease outcomes, including reduced incidence of stroke [1-3] and heart failure [4], and reduced mortality from ischemic heart disease $[5,6]$ and sudden cardiac events $[7,8]$. Fish is a rich source of long chain omega-3 polyunsaturated fatty acids (LC omega-3 PUFA), protein and other nutrients such as selenium, vitamin D and taurine [9]. As with many health organizations around the world, the Heart Foundation recommends Australians consume two to three serves of fish per week [10], however survey data suggests on average Australian adults are not meeting this recommendation [11]. This suggests that whilst the efficacy of fish consumption is well proven, the effectiveness of such recommendations is problematic in the free-living setting.

Health professionals, and notably dietitians can influence eating behavior via nutrition education [12]; however, little research has focused on the impact of such

\footnotetext{
"The authors declare no conflict of interest.
}

education on fish consumption behavior. In particular, there is a scarcity of research investigating whether specific fish consumption advice incorporating dietary targets is advantageous in increasing fish intake behavior, compared to general healthy eating advice. Furthermore, few clinical trials investigate the effectiveness of fish consumption recommendations. A 12-month dietary trial examining the effect of LC omega-3 PUFA on weight loss, which utilizes specific and general fish consumption advice, provides a vehicle to investigate the differential effects of such advice on fish consumption and the adherence to the advice over the duration of the study. The aim of the present study was to examine the effect of general dietary advice on fish intake compared to advice specifically emphasizing targets for fish consumption over the duration of a 12-month dietary trial.

\section{Experimental Section}

\subsection{Study Design}

The dietary intervention from which data were obtained for this analysis was a twelve month parallel designed 
randomized controlled trial [13] conducted in Wollongong, a major coastal city just south of Sydney, Australia. The randomized controlled trial is registered with the Australian New Zealand Clinical Trials Registry (ACTRN12608000425392, www.anzctr.org.au). Participants were randomly assigned to one of three diet groups: general dietary advice with daily placebo capsules $(1 \mathrm{~g}$ olive oil) (control group, C), general dietary advice plus additional advice to consume fish with daily placebo capsules (1g olive oil) (Fish group), and general dietary advice plus additional advice to consume fish with fish oil capsules $(640 \mathrm{mg}$ eicosapentaenoic acid and docosahexaenoic acid) (Fish $+\mathrm{S}$ group). All participants received counseling on a healthy food plan with a 2 MJ deficit (including avoidance of high fat foods and use of low fat staple foods) provided by Accredited Practising Dietitians. All participants received individualized, face-toface education sessions with a dietitian, consisting of dietary education (1 hour) and follow-up (30 minutes) sessions at baseline, 1, 2, 3, 6, 9, 12 months. Participants in both the "Fish" and "Fish $+\mathrm{S}$ " groups were specifically instructed to consume 180 grams of fish per week, with an emphasis on consumption of fatty fish high in LC omega-3 PUFA. This prescription was supported by print materials on fish based recipes and meal ideas. Participants in the control group were not given specific advice regarding fish intake, but were instructed to consume a specific amount of foods rich in protein, of which fish was an option. As the "Fish" and "Fish + S" groups were both given the same advice regarding fish consumption, they were combined into one group for all further analyses in the present study ("Fish advice").

\subsection{Participants}

Participants were recruited from the local community by media advertising. Inclusion criteria were aged $18-60$ years, body mass index $(\mathrm{BMI})>25$ and $<37 \mathrm{~kg} / \mathrm{m}^{2}$, waist circumference $>94 \mathrm{~cm}$ for men, $>80 \mathrm{~cm}$ for women, generally well. Exclusion criteria were major illnesses, diabetes mellitus, $\mathrm{LDL} \geq 6 \mathrm{mmol} / \mathrm{L}$, food allergies or habits inhibiting compliance, illiteracy, inadequate conversational English, taking fish oil supplements, inability to undertake study requirements, pregnancy/lactation, not weight stable(within $3 \mathrm{~kg}$ ) past $6 \mathrm{mo}$, on a weight-reducing diet. Ethical approval for the research was provided by the University of Wollongong Human Research Ethics Committee. Signed consent was given by all participants.

\subsection{Measurement of Fish Consumption}

Dietary information was collected by Accredited Practising Dietitians at baseline, 3 months and 12 months via a validated diet history [14]. Dietary data was entered into Foodworks (Xyris Software, Version 5, 2007), using the "AUSNUT All Foods" and "AUSbrands" databases. Where possible, nutritional data for specific brands and products was entered into the database.

Fish intake was calculated as grams of fish consumed per day, and the percentage fish in each dish or product calculated based on a validated approximation of canned fish labels [15] and standardized recipe data. Fish consumed were then classified as either lean or fatty fish, based on a combination of the cut-off levels proposed by Mina et al. [16] and Devore et al. [17] for total fat and LC omega-3 PUFA respectively. For example, fish classified as fatty included fresh and canned salmon, gemfish, silver perch and trout.

\subsection{Statistical Analysis}

The analysis reported here was a secondary analysis from a trial powered to test differences in weight loss. For this analysis, data was analyzed using SPSS (version 17.0, SPSS Chicago, IL, 2008). As a result of the skewed nature of the data, median and range of grams of total, fatty and lean fish consumed were calculated for each study group rather than mean. Normality of the data was determined using the Shapiro-Wilks test. The change in fish consumption within groups over the duration of the trial was determined using the Friedman test. Change in fish consumption between groups at each time point was measured using the Mann-Whitney test. In this analysis we were interested in the actual on treatment compliance of the subjects participating in the study. Although the dropout rate in the trial was substantial and the complete case analysis may affect the generalisability of the results to a larger population [18], intention to treat analysis and imputation approaches were not considered here as the interest was on the actual behavior of the study participants. This completers only approach has previously been used in assessing dietary adherence as a secondary analysis [19]. The issue of study dropout was considered in the primary analysis where several approaches were used to address the validity of the results for the primary outcome of weight change [13].

Trial participants were then classified as either meeting or not meeting the Smart trial fish intake recommendations (180 grams of fish per week). The percentage of participants reaching the trial recommendations was then calculated. Pearson chi-square analysis was used to determine if there was a significant difference between the proportions of participants meeting fish intake recommendations in the trial groups at each time point.

\section{Results}

One hundred and eighteens participants were enrolled in the study at baseline, 86 remained at 3 months, and 64 
remained at 12 months. One participant was excluded from all further analysis due to implausible fish intake. At baseline, the mean age of participants was $45.47 \pm$ 8.50 years. On average participants were obese, with a body mass index of $31.30 \pm 3.50 \mathrm{~kg} / \mathrm{m}^{2}$, and predominantly female $(75.2 \%)$. Missing data was the result of study dropouts, however, as was previously highlighted, as this was a secondary analysis of a randomized controlled trial with an objective of measuring change in fish consumption over time, data analysis was performed on the subset of data available. Data is presented for only those participants with dietary data available at all three time points $(n=63)$. There were no significant changes in the median amount of total fish consumed within groups over time or between groups at any time point in the study (Table 1).

However, when values for the median and range of categories of fish consumption were considered, significant results emerged (Table 2). Participants in the control group consumed significantly less fatty fish at the three month time point than the "Fish advice" group $(\mathrm{p}=$ 0.004).

The proportion of trial participants meeting the trial fish consumption recommendations is shown in Table 3. A Pearson chi-square analysis indicated there were no significant differences between the proportion of participants in the "Fish advice" or control groups meeting the total fish consumption recommendation at baseline $\left[\chi^{2}(1)\right.$ $=0.345, \mathrm{p}=0.557], 3$ months $\left[\chi^{2}(1)=2.714, \mathrm{p}=0.099\right]$, or 12 months $\left[\chi^{2}(1)=0.027, \mathrm{p}=0.870\right]$.

\section{Discussion}

The results of this study suggest that specific advice to increase fish consumption to 180 grams per day was most effective in the first three months of a dietary trial. This pattern of fish consumption was the result of significantly higher consumption of fatty fish rich in LC omega-3 PUFA in the "Fish advice" group at the three month time point, with the increase in total fish at this time point not reaching statistical significance.

In the present study, specific fish consumption advice appeared to be less effective after three months, with decreased adherence to recommended fish consumption targets in the "fish advice" group after this time. Decreased levels of adherence over the duration of longterm dietary trials have been reported in other studies of a comparable duration [20,21], and may be the result of participant fatigue over the course of a twelve month trial. In addition, the structure of the present trial was such that the first three months involved intensive sessions with a dietitian, which became less intensive in the last nine months of the trial. Regular nutritional follow-up has been shown to be associated with increased adherence to dietary trial regimes [22]. The reduction in compliance to the fish intake recommendations in the present study, which coincided with fewer dietitian appointments, highlights the importance of continuing nutrition intervention and support in facilitating ongoing dietary change.

Nutrition intervention incorporating specific fish consumption advice was also seen to influence the type of

Table 1. Median (interquartile range) total fish (grams/day) consumed at baseline, three and twelve months by study group.

\begin{tabular}{ccccc}
\hline Study group & Baseline & 3 months & 12 months & Friedman test p-value \\
\hline $\begin{array}{c}\text { "Fish advice" } \\
\text { grams/day) }\end{array}$ & $25.34(10.24-42.03)$ & $33.55(22.28-52.11)$ & $34.33(17.53-62.85)$ & 0.072 \\
Control (grams/day) & $27.10(11.80-81.93)$ & $28.57(19.66-45.93)$ & $28.06(15.77-59.38)$ & 0.790 \\
Mann-Whitney p-value & 0.311 & 0.219 & 0.739 & \\
\hline
\end{tabular}

Table 2. Median (interquartile range) fatty and lean fish (grams/day) consumed at baseline, three and twelve months by study group.

\begin{tabular}{|c|c|c|c|c|c|}
\hline \multicolumn{2}{|c|}{ Study group } & \multirow{2}{*}{ Baseline } & \multirow{2}{*}{3 months } & \multirow{2}{*}{12 months } & \multirow{2}{*}{ Friedman test p-value } \\
\hline & Fish category & & & & \\
\hline \multirow{2}{*}{ "Fish advice" } & Fatty (grams/day) & $0.50(0.00-13.42)$ & $10.20(0.00-24.07)$ & $1.08(0.00-13.76)$ & 0.176 \\
\hline & Lean (grams/day) & $16.06(6.64-39.55)$ & $22.81(10.91-38.13)$ & $22.27(9.95-45.37)$ & 0.218 \\
\hline Control & Lean (grams/day) & $22.86(9.61-62.29)$ & $25.71(10.10-41.16)$ & $22.19(15.46-52.02)$ & 0.662 \\
\hline \multirow{2}{*}{$\begin{array}{c}\text { Mann-Whitney } \\
\text { p-value }\end{array}$} & Fatty & 0.201 & 0.004 & 0.303 & \\
\hline & Lean & 0.508 & 0.793 & 0.609 & \\
\hline
\end{tabular}


Table 3. Proportion study participants meeting recommendation to consume $180 \mathrm{~g}$ fish per week at baseline, three and twelve months.

\begin{tabular}{cccc}
\hline Study group & Baseline & 3 months & 12 months \\
\hline "Fish advice" & $23 / 46(50 \%)$ & $32 / 46(69.6 \%)$ & $26 / 46(56.5 \%)$ \\
Control & $9 / 17(52.9 \%)$ & $9 / 17(52.9 \%)$ & $10 / 17(68.8 \%)$ \\
\hline
\end{tabular}

fish consumed in the trial. Significant differences in the consumption of fatty fish were seen between the control and "Fish advice" groups at the three month time point (Table 2). As the intervention groups were advised to consume fatty fish preferentially, this suggests that specific nutrition advice favorably influenced participant's abilities to reach targets for the type in addition to the amount of fish. However, total, fatty and lean fish consumption varied greatly between individuals, irrespective of study group (Tables 1 and 2). These findings suggest that future efforts to alter fish consumption behavior may benefit from individualized nutrition advice which takes into account baseline fish consumption to assist in meeting dietary targets.

The proportion of participants meeting the fish consumption targets of the current study were substantially lower than those reported in similar studies in the literature, which often report over $90 \%$ adherence to study recommendations [23-26]. It should be noted however that these studies provided participants with the recommended amount of fish to assess the efficacy of fish consumption on health. Provision of food products has been shown to increase compliance to dietary interventions and resultant health outcomes [27-29]. The present study gave structured dietary advice based on specific food groups and portion sizes, which mimics that received in the clinical dietetic setting, and is thus a good model to assess the effectiveness of such advice. Whilst long-term provision of specific fish consumption advice did result in some increases in fish intake, many participants did not reach the targets of the present study. Comparison of fish consumption in the present study with the National Heart Foundation's recommendation to consume at least 300 grams of fish per week revealed that even fewer participants met this criteria (data not shown), raising the question of the achievability of these recommendations.

Furthermore, whilst the results of this study suggest that that a substantial proportion of the study sample did not reach the targets for fish consumption, this may have been in part due to methodological issues associated with measurement of fish intake. For example, canned tuna products, which made up approximately one third of the fish consumed at each time point (data not shown), have been found to contain on average $60.4 \%$ fish [15], thus individuals may overestimate their fish consumption from these product. In the present study, fish consumption measurements were adjusted to account for the percentage fish contained in such products. The implementation of nutrition interventions which educate participants on the amount of fish contained in canned products may overcome this problem, and may be a strategy to facilitate changes in fish consumption behavior in both clinical trials and the free-living environment.

Measurement of fish consumption in the present study was based on self-reported data taken via a diet history, which is reliant on memory and is susceptible to reporting bias [30], which could be a limitation of this research. In the present study, however, changes in the omega-3 index, an objective measure of LC omega-3 intake [31], were indicative of fish consumption in the trial groups [13], supporting fish consumption as reported by study participants. In addition, the analysis is limited by the study context including the participation of motivated volunteers for a dietary trial and the large amount of drop-outs in the parent trial, thus it is not possible to generalize these results to the wider population. However, as a case study in providing dietary advice on fish intake this study provides insights for developing nutrition education strategies to increase consumption of this nutrient rich food.

\section{Conclusion}

Fish is a rich source of many nutrients and habitual consumption is known to be associated with a number of health benefits. However, as fish intake is known to be low in many developed countries, research needs to consider the effectiveness of consumption targets and develop practical strategies to increase these levels. The findings of this study suggest that specific fish consumption advice was most effective at increasing fish intake behavior in the first three months of a dietary trial. Maintenance of frequent nutrition follow-up after this point may have avoided decreases in the proportion of participants meeting fish consumption targets seen over the remainder of the trial. Future dietary studies may find that providing advice regarding portion sizes of canned products in addition to specific fish intake advice improves participant's abilities to meet fish consumption targets. Future efforts to ensure effective fish consumption behavior may be aided by providing ongoing support following fish intake advice and by basing such advice on individual's initial fish consumption habits.

\section{Acknowledgements}

The 12-month clinical trial was funded by a NHMRC project grant (\#514631) Tapsell, Batterham, Charlton. Elizabeth Neale was supported by an Australian Post- 
graduate Award scholarship.

\section{REFERENCES}

[1] H. Iso, K. M. Rexrode, M. J. Stampfer, J. E. Manson, G. A. Colditz, F. E. Speizer, C. H. Hennekens and W. C. Willett, "Intake of Fish and Omega-3 Fatty Acids and Risk of Stroke in Women," Journal of the American Medical Association, Vol. 285, No. 3, 2001, pp. 304-312. doi:10.1001/jama.285.3.304

[2] K. He, E. B. Rimm, A. Merchant, B. A. Rosner, M. J. Stampfer, W. C. Willett and A. Ascherio, "Fish Consumption and Risk of Stroke in Men," Journal of the American Medical Association, Vol. 288, No. 24, 2002, pp. 3130-3136. doi:10.1001/jama.288.24.3130

[3] D. Mozaffarian, W. T. Longstreth, Jr., R. N. Lemaitre, T. A. Manolio, L. H. Kuller, G. L. Burke and D. S. Siscovick, "Fish Consumption and Stroke Risk in Elderly Individuals: The Cardiovascular Health Study," Archives of Internal Medicine, Vol. 165, No. 2, 2005, pp. 200-206. doi:10.1001/archinte.165.2.200

[4] E. B. Levitan, A. Wolk and M. A. Mittleman, "Fish Consumption, Marine Omega-3 Fatty Acids, and Incidence of Heart Failure: A Population-Based Prospective Study of Middle-Aged and Elderly Men," European Heart Journal, Vol. 30, No. 12, 2009, pp. 1495-1500.

doi:10.1093/eurheartj/ehp111

[5] D. Mozaffarian, R. N. Lemaitre, L. H. Kuller, G. L. Burke, R. P. Tracy and D. S. Siscovick, "Cardiac Benefits of Fish Consumption May Depend on the Type of Fish Meal Consumed: The Cardiovascular Health Study," Circulation, Vol. 107, No. 10, 2003, pp. 1372-1377. doi:10.1161/01.CIR.0000055315.79177.16

[6] K. Yamagishi, H. Iso, C. Date, M. Fukui, K. Wakai, S. Kikuchi, Y. Inaba, N. Tanabe and A. Tamakoshi, "Fish, [Omega]-3 Polyunsaturated Fatty Acids, and Mortality From Cardiovascular Diseases in a Nationwide Community-Based Cohort of Japanese Men and Women: The JACC (Japan Collaborative Cohort Study for Evaluation of Cancer Risk) Study," Journal of the American College of Cardiology, Vol. 52, No. 12, 2008, pp. 988-996. doi:10.1016/j.jacc.2008.06.018

[7] C. M. Albert, C. H. Hennekens, C. J. O'Donnell, U. A. Ajani, V. J. Carey, W. C. Willett, J. N. Ruskin and J. E. Manson, "Fish Consumption and Risk of Sudden Cardiac Death," Journal of the American Medical Association, Vol. 279, No. 1, 1998, pp. 23-28. doi:10.1001/jama.279.1.23

[8] M. T. Streppel, M. C. Ocke, H. C. Boshuizen, F. J. Kok and D. Kromhout, "Long-Term Fish Consumption and n-3 Fatty Acid Intake in Relation to (Sudden) Coronary Heart Disease Death: The Zutphen Study," European Heart Journal, Vol. 29, No. 16, 2008, pp. 2024-2030. doi:10.1001/jama.279.1.23

[9] I. Thorsdottir, H. Tomasson, I. Gunnarsdottir, E. Gisladottir, M. Kiely, M. Parra, N. Bandarra, G. Schaafsma and J. Martinez, "Randomized Trial of Weight-Loss-Diets for Young Adults Varying in Fish and Fish Oil Content," International Journal of Obesity, Vol. 31, No. 2007, pp.
1560-1566.

[10] The National Heart Foundation, "Heart Foundation Position Statement: Fish, Fish Oils, n-3 Polyunsaturated Fatty Acids and Cardiovascular Health," 2008. http://www.heartfoundation.org.au/SiteCollectionDocume nts/Fish-position-statement.pdf

[11] Australian Bureau of Statistics, "National Nutrition Survey: Foods Eaten," Canberra, 1995.

[12] M. T. Timin, K. V. Shores and M. Reicks, "Behavior Change Outcomes in an Outpatient Cardiac Rehabilitation Program," Journal of the American Dietetic Association, Vol. 102, No. 5, 2002, pp. 664-671. doi:10.1016/S0002-8223(02)90152-5

[13] L. C. Tapsell, M. J. Batterham and K. E. Charlton, "Effects of n-3 Fatty Acids on Weight Loss: A 1 Year Randomized Controlled Trial," The FASEB Journal, Vol. 25, No. 1, 2011, pp. 774-775.

[14] G. S. Martin, L. C. Tapsell, S. Denmeade and M. J. Batterham, "Relative Validity of a Diet History Interview in an Intervention Trial Manipulating Dietary Fat in the Management of Type II Diabetes Mellitus [Small Star, Filled]," Preventive Medicine, Vol. 36, No. 4, 2003, pp. 420-428. doi:10.1016/S0091-7435(02)00054-3

[15] E. Neale, Y. Probst, M. Batterham and L. Tapsell, "Development and Validation of an Australian Database for Estimating the Seafood Content of Canned Products," Food and Nutrition Sciences, Vol. 2, No. 7, 2011, pp. 759-763. doi:10.4236/fns.2011.27104

[16] K. Mina, L. Fritschi and M. Knuiman, "A Valid Semiquantitative Food Frequency Questionnaire to Measure Fish Consumption," European Journal of Clinical Nutrition, Vol. 61, No. 8, 2007, pp. 1023-1031. doi:10.1038/sj.ejen.1602617

[17] E. E. Devore, F. Grodstein, F. J. A. van Rooij, A. Hofman, B. Rosner, M. J. Stampfer, J. C. M. Witteman and M. M. B. Breteler, "Dietary Intake of Fish and Omega-3 Fatty Acids in Relation to Long-Term Dementia Risk," American Journal of Clinical Nutrition, Vol. 90, No. 1, 2009, pp. 170-176. doi:10.3945/ajen.2008.27037

[18] C. Enders, “Applied Missing Data Analysis,” The Guilford Press, New York, 2010.

[19] S. Alhassan, S. Kim, A. Bersamin, A. King and C. Gardner, "Dietary Adherence and Weight Loss Success among Overweight Women: Results from the A to Z Weight Loss Study," International Journal of Obesity, Vol. 32, No. 2008, pp. 985-991.

[20] L. C. Tapsell, M. J. Batterham, G. Teuss, S. Y. Tan, S. Dalton, C. J. Quick, L. J. Gillen and K. E. Charlton, "Long-Term Effects of Increased Dietary Polyunsaturated Fat from Walnuts on Metabolic Parameters in Type II Diabetes," European Journal of Clinical Nutrition, Vol. 63, No. 8, 2009, pp. 1008-1015. doi:10.1038/ejen.2009.19

[21] M. L. Dansinger, J. A. Gleason, J. L. Griffith, H. P. Selker and E. J. Schaefer, "Comparison of the Atkins, Ornish, Weight Watchers, and Zone Diets for Weight Loss and Heart Disease Risk Reduction: A Randomized Trial," Journal of the American Medical Association, Vol. 293, No. 1, 2005, pp. 43-53. doi:10.1001/jama.293.1.43 
[22] K. Markwell, S. Somerset, F. Rowe and S. Borbasi, "What Contributes to Weight Loss Dietary Adherence? Results of a Psychosocial Investigation," Australasian Medical Journal, Vol. 3, No. 1, 2010, p. 102.

[23] I. Thorsdottir, B. Birgisdottir, M. Kiely, J. Martinez and N. Bandarra, "Fish Consumption among Young Overweight European Adults and Compliance to Varying Seafood Content in Four Weight Loss Intervention Diets," Public Health Nutrition, Vol. 12, 2009, pp. 592-598.

[24] T. A. Mori, R. Vandongen, L. J. Beilin, V. Burke, J. Morris and J. Ritchie, "Effects of Varying Dietary Fat, Fish, and Fish Oils on Blood Lipids in a Randomized Controlled Trial in Men at Risk of Heart Disease," American Journal of Clinical Nutrition, Vol. 59, No. 5, 1994, pp. 1060-1068.

[25] K. Kondo, K. Morino, Y. Nishio, M. Kondo, T. Fuke, S. Ugi, H. Iwakawa, A. Kashiwagi and H. Maegawa, "Effects of a Fish-Based Diet on the Serum Adiponectin Concentration in Young, Non-Obese, Healthy Japanese Subjects," Journal of Atherosclerosis and Thrombosis, Vol. 17, No. 6, 2010, pp. 628-637. doi: $10.5551 /$ jat. 3657

[26] J. J. Lara, M. Economou, A. M. Wallace, A. Rumley, G. Lowe, C. Slater, M. Caslake, N. Sattar and M. E. J. Lean, "Benefits of Salmon Eating on Traditional and Novel Vascular Risk Factors in Young, Non-Obese Healthy
Subjects," Atherosclerosis, Vol. 193, No. 1, 2007, pp. 213-221. doi:10.1016/j.atherosclerosis.2006.06.018

[27] R. R. Wing and R. W. Jeffery, "Food Provision as a Strategy to Promote Weight Loss," Obesity, Vol. 9, No. 11S, 2001, pp. 271S-275S. doi:10.1038/oby.2001.130

[28] R. W. Jeffery, R. R. Wing, C. Thorson, L. R. Burton, C. Raether, J. Harvey and M. Mullen, "Strengthening Behavioral Interventions for Weight Loss: A Randomized Trial of Food Provision and Monetary Incentives," Journal of Consulting \& Clinical Psychology, Vol. 61, No. 6, 1993, pp. 1038-1045. doi:10.1037/0022-006X.61.6.1038

[29] J. A. Metz, P. M. Kris-Etherton, C. D. Morris, V. A. Mustad, J. S. Stern, S. Oparil, A. Chait, R. B. Haynes, L. M. Resnick, S. Clark, et al., "Dietary Compliance and Cardiovascular Risk Reduction with a Prepared Meal Plan Compared with a Self-Selected Diet," American Journal of Clinical Nutrition, Vol. 66, No. 2, 1997, pp. 373-385.

[30] F. E. Thompson and T. Byers, "Dietary Assessment Resource Manual," Journal of Nutrition, Vol. 124, No. 11, 1994, pp. $2245 \mathrm{~s}-2317 \mathrm{~s}$

[31] W. S. Harris and C. von Schacky, "The Omega-3 Index: A New Risk Factor for Death from Coronary Heart Disease?" Preventive Medicine, Vol. 39, No. 1, 2004, pp. 212-220. doi:10.1016/j.ypmed.2004.02.030 